\title{
Geography and Entrepreneurship
}

\author{
Martin Andersson and Johan P. Larsson
}

\section{Contents}

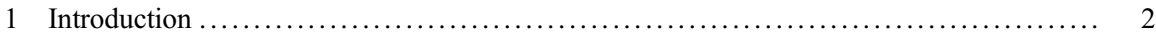

2 Why Study the Geography of Entrepreneurship? .............................. 3

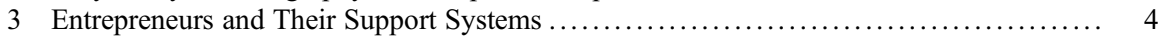

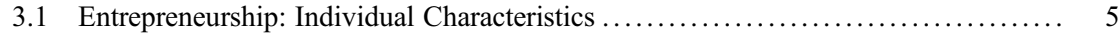

3.2 Entrepreneurship: Demand Factors .................................... 5

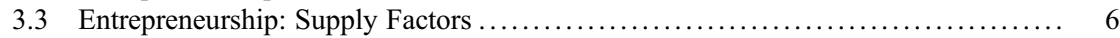

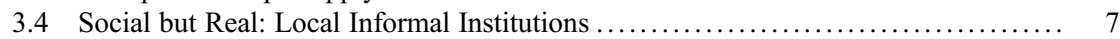

3.5 Local Formal Institutions: Permits and Politics .............................. 9

3.6 The "Correct" Spatial Level of Observation ................................ 9

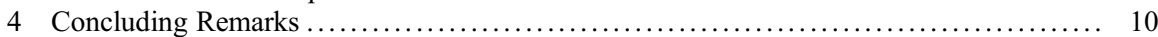

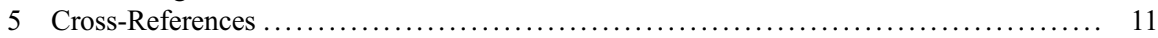

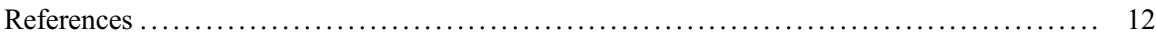

\begin{abstract}
We take selective stock of the literature on the geography of entrepreneurship. This literature has been focused on rates of new firm formation, whereas studies of the geography of "high-impact" entrepreneurship are still scant.
\end{abstract}

M. Andersson

Department of Industrial Economics, Blekinge Institute of Technology, Karlskrona, Sweden

Swedish Entrepreneurship Forum, Stockholm, Sweden

Research Institute of Industrial Economics, Stockholm, Sweden

CIRCLE, Lund University, Lund, Sweden

e-mail: martin.andersson@bth.se

J. P. Larsson $(\bowtie)$

Swedish Entrepreneurship Forum, Stockholm, Sweden

Department of Land Economy, University of Cambridge, Cambridge, UK

Centre for Entrepreneurship and Spatial Economics, Jönköping University, Jönköping, Sweden e-mail: jp166@cam.ac.uk 
Entrepreneurship may be described as a "regional event" by the fact that entrepreneurs derive necessary resources from local markets, but also from regional spillovers, social networks, and engrained factors of the local industrial geography. We point to a few fields of analysis where causal or more detailed analyses are warranted.

\section{Keywords}

Entrepreneurship · Regional development - Geography of entrepreneurship

\section{Introduction}

Perhaps the only thing ubiquitous about entrepreneurship is its great variability. The renewal frequency of new firms and their growth ambitions, the "quality" of existing entrepreneurship, and many aspects of the entrepreneurs themselves vary among groups of people and hence across the map. Economic geographers and regional scientists have devoted much attention to better understand the relationship between local conditions and entrepreneurship. The main empirical regularity that has been subject to investigation in this literature is the sources of spatial variations in local rates of new firm formation (Fritsch and Storey 2014).

The link between entrepreneurship and growth is generally well-established. Entrepreneurship is also typically seen as an important mechanism by which the economy introduces novelty and experiment with new technology, knowledge, and solutions (Kerr et al. 2014; Lindholm-Dahlstrand et al. 2019). Because our economies are renewing and changing at a fast rate and we face significant challenges, such as climate change, the agents that bring about structural change and develop new solutions are more relevant than they have ever been (Wennekers and Thurik 1999).

At the local level, a large literature analyzes the effect of local rates of new firm formation on regional growth and development. A growing body of evidence now supports the view that a high rate of local new firm formation boosts growth and development (Glaeser et al. 2015; Fritsch 2013). The evidence is also increasingly causal: entrepreneurs do not just follow growth - they lead it (e.g., Glaeser et al. 2015; Lee 2017). That is, if some places exhibit consistently higher start-up rates over a sustained time period, we should all else equal also expect those places to pull ahead in terms of growth rates and development.

Our understanding of the quality of entrepreneurship has improved as well. A cornerstone of the Global Entrepreneurship Monitor (GEM) project, for instance, is the ambition to give researchers tools to analyze different types of entrepreneurship. This perspective has to date not been sufficiently extended to regional science and economic geography. A main task for economic geography in the twenty-first century should be to elucidate determinants and consequences of the quantity and the quality of local entrepreneurship, as well as the torrent of ripple effects that entrepreneurship has through local institutions and labor markets. 
To understand the geography of entrepreneurship, we need to elucidate at least three broad categories of explanations for the frequency and quality of entrepreneurship, including the interactions of those categories. First, we need to understand which individuals are more likely to start firms and how such individuals sort themselves across the geography. This category includes analyses of personal characteristics of the entrepreneurs, such as their personality and demography, and their location choices. Second, we need to understand the role of supply- and demand-side factors, including how entrepreneurs benefit from spillover effects and local market potential. Third, we need to understand the role that formal and informal institutions play in fostering (or hindering) entrepreneurial behaviors and how such institutions are developed and maintained over time. For instance, simply because a region has good "economic fundamentals" and individuals that spot entrepreneurial opportunities, it does not imply that the individuals choose to act. New firms are started by people who act on perceived opportunities, and their decision to act or not is influenced by local institutions, e.g., in the form of social acceptance of entrepreneurship as well as the formal regulatory and policy environment.

Regional science has much to say about all three categories of explanations. This chapter presents a selective summary of the literature on the geography of entrepreneurship. In Sect. 2 we first provide some arguments as to why the geography of entrepreneurship matters. Section 3 then reviews main supply- and demand-side factors that determine the local presence of entrepreneurship. Section 4 concludes.

\section{Why Study the Geography of Entrepreneurship?}

Entrepreneurs are widely acknowledged to be important "change agents" in the economy (Acs et al. 2009): it is the entrepreneur who finds and recognizes entrepreneurial opportunities and amasses enough resources and courage to act upon the opportunity. The entrepreneur will, as a by-product, spread knowledge of opportunities and of ways of working and lead by example to inspire others in their social surroundings.

One perspective on the entrepreneur has its roots in the Schumpeterian school of thought and builds on Schumpeter's notion of "creative destruction." According to this view, entrepreneurs drive growth and economic dynamism by introducing innovations, new technology, and new ways of doing business. This perspective puts emphasis on "high-quality" and innovative new firms that disrupt established business models and bring new technologies and knowledge to the market. Another perspective on entrepreneurship is provided by Kirzner (1973) who emphasizes that entrepreneurship also has an equilibrating role in the economy. Examples of such entrepreneurship are new businesses of more mundane forms, such as coffee shops, restaurants, and electricians, which develop to satisfy local demand. While some scholars argue that genuine entrepreneurship should mainly be thought of as being of the former kind (Henrekson and Sanandaji (2014)), in the context of regional growth 
and development, there are arguments in favor of that both Schumpeterian and Kirznerian types of new businesses matter.

Schumpeterian new firms may constitute an important function by creating jobs, induce structural change, and drive the creation of novelty in cities and regions. But more mundane forms of new business also matter at the local level for several reasons, even if the growth potential of individual firms may be limited. First, new firms in mundane activities, like regular restaurants, coffee shops, carpentry, and so on, fulfill an important function by developing a city's or region's variety of consumer and producer services that help in shaping the overall attractiveness of the place. Such business are, for example, vital in so-called placemaking. Second, new firm formation in mundane types of activities also implies an increase in the presence of local role models which develops knowledge and information about the practice of running a business. This may help to develop a local "culture of entrepreneurship" (cf. Fritsch and Wyrwich 2014; Andersson and Larsson 2016; Minniti 2005), and a higher density of local entrepreneurs may create pressure on local policymakers to develop regulations and enforcement procedures that are more business-friendly (Andersson and Henrekson 2015). Third, even in its most mundane form, entrepreneurship can lift at least one person out of dependence on social support or other people, namely, the entrepreneur himself. Finally, even business owners with the lowest of aspirations may run into unexpected opportunity to grow their business and/or draw on their experience and start another business in a new niche, even if by chance and not part of their initial plan.

The empirical literature on the effect of new firm formation on regional growth and development typically finds significant positive effects of on long-run employment growth (see Fritsch 2013, for a survey). Many papers in this vein examine the influence of the overall rate of new firm formation, small business density, or selfemployment rates, and such measures are more likely to capture everyday entrepreneurship, rather than "radical" and high-potential start-ups (cf. Henrekson and Sanandaji 2014). This debate points to the wider role of new firm formation in regional growth and development, but also points to broadening our conception of "entrepreneurship."

\section{Entrepreneurs and Their Support Systems}

This section proceeds by tracing the role of entrepreneurs and their interaction with the local milieu. Most arguments below are in principle valid whether we are talking about a high-impact entrepreneur in the Schumpeterian tradition or a marginal improver in the Kirznerian sense. However, it is easy to see that several of the arguments presented below will be more relevant for one or the other. For instance, an entrepreneur planning to grow their business into new markets would seem to benefit more from access to highly skilled labor compared to entrepreneurs with more mundane ambitions.

The introduction made the case that "what causes entrepreneurship" can be understood along three dimensions in an economic-geographic analysis: 
(i) individual characteristics, (ii) market potential and access to inputs, and (iii) formal and informal institutions. In this section we organize our discussion around these broad categories and close this section with a short note on spatial scale of the analysis.

\subsection{Entrepreneurship: Individual Characteristics}

Personal characteristics, acquired ones and inherited ones, are important for an individual's decision to act entrepreneurially. Several personal characteristics and experiences correlate strongly with the decision to form a new venture (e.g., labor market experience, previous wage, age, employment status, and personality types/ traits) which means that the distribution across space of people with respect to those factors should be important for anyone who researches the economic geography of entrepreneurship.

Other characteristics are ambiguous in terms of their influence on the average start-up decision but may importantly influence the quality of the entrepreneurial effort (e.g., human capital, previous occupation, and previous employer size). For instance, a robust observation in studies of entrepreneurship is that entrepreneurs with high measures of human capital run more impactful businesses. That is to say, we should expect regions to be high in entrepreneurial potential if they attract individuals with those characteristics or manage to foster those characteristics among their current inhabitants. In their regional analysis covering 97 percent of the world's GDP, Gennaioli et al. (2013) conclude that the main factors explaining cross-regional divergence in regional development are human capital and entrepreneurial inputs and their interaction.

Our knowledge of how spatial sorting of human capital impact the geography of entrepreneurship is also growing. There are, for example, recent studies of the spatial distribution of personality types/traits. Obschonka et al. (2013) employ large datasets from the USA, UK, and Germany and demonstrate substantial correlations between the spatial distribution of a Big Five personality profile deemed to be entrepreneurship-prone and the corresponding distribution of entrepreneurial activity.

\subsection{Entrepreneurship: Demand Factors}

The population of the local economy will reflect, first, the scale and, second, the diversity potential of local demand. The scale is important because it allows more production to be performed locally. Jane Jacobs' (1969) main argument is built on how import is substituted away in larger places. Import substitution leads to division of labor and makes the city ever more productive in meeting local demand. New firms, particularly new large firms, may be stimulated by high local division of labor and may be motivated to invest in businesses with higher fixed costs and higher break-even points than they otherwise would. 
As specialization and size are intimately connected, so are size and diversity. The diversity of production of the local economy is directly limited by the extent of the market. Most large-scale services that are difficult to import may serve as good examples. If an opera house is in use by $1 \%$ of the population and needs 10,000 paying customers per year to sustain its business, then it needs a customer catchment area covering at least $1,000,000$ people. In principle the argument is valid for any activity that requires substantial critical mass (e.g., elite sports teams) or that is enjoyed by a small part of the population (e.g., avant-gardist art). Similar argument can be made for the breadth of demand in areas like food and shopping, where the newest and most niched restaurants and stores are mostly patronized in and around the metropolitan landscape. In the literature on immigrant entrepreneurship, for instance, a common argument is that a local density of immigrants may create local demand for specific types of services (restaurants, grocery stores, medical services, etc.) that stimulate immigrant businesses (Aldrich et al. 1985).

Local diversity of products and services also make it possible for dense regions to sustain an equally impressive range of lifestyles, as well as a swiftly expanding range of ways of life. Hence, potential entrepreneurs with knowledge about these lifestyles, combined with a willingness to put that knowledge to the commercial test, will become increasingly concentrated in such places where those lifestyles are present.

Finally, it should be noted that the role of demand factors certainly depends on the nature of businesses. For example, demand-side factors are in general more important in explaining the geography of entrepreneurship in industries or activities that rely on local markets, such as various local service businesses (see, e.g., Andersson et al. 2019b).

\subsection{Entrepreneurship: Supply Factors}

A key supply-side factor that influences the geography of entrepreneurship is human capital. The skills of the local work force are a key input for new as well as established firms. The range and width of human capital, including the overall skills used in knowledge-intensive production, are both typically concentrated to large city regions, and this is one explanation for why large city regions are often described as "hotbeds" for entrepreneurship. Other than implying that access to cutting-edge knowledge is available locally, more highly skilled local people implies a more skilled pool of potential and current entrepreneurs. These and other factors described in this section contribute to a substantial modernity gap in the nature and type of entrepreneurship observed in different parts of the regional hierarchy (Andersson and Koster 2016).

Aside from traditional supply factors, there are also supply-side factors that relate to the classic agglomeration economies. A key characteristic of the firm in the regional sciences is the idea that it can usurp various spillovers from its surroundings via local increasing returns that are external to the firm, but internal to places where other firms have already agglomerated. Duranton and Puga (2004) classify the 
micro-foundations of such agglomeration economies into sharing, matching, and learning.

Sharing refers to the ability of firms to share input suppliers or large investments in indivisibles. These benefits make investments in city walls, education institutions, and town squares viable, but also mean that firms in dense areas have a richer ecosystem of input suppliers, including specialized legal advice and other business services.

Matching refers to that density of economic activity bodes for more efficient matching of skills to occupations, tastes to demands, and so on that necessarily results from thicker markets with consequently more people with specialized profiles and employers with specialized demands. This mechanism implies that cities are simply the place to be for whoever wants to produce (by running a firm or working in one) at the higher end of international value chains.

Learning, finally, refers to conscious and unconscious knowledge and information spillover that are driven by nonmarket interactions. The tendency for the potential for such interactions to diminish particularly swiftly with space gives geography a unique role for facilitating this type of spillover, an idea to which we return below. This mechanism can further be expected to be more important the more knowledge-intensive is the area under study, as this type of spillover is more important when the knowledge that we are trying to piece together is incomplete or very new.

Conceptually, it is natural to assume that these spillovers - whether characterized by sharing, matching, or learning - matter differently for Schumpeterian and Kirznerian entrepreneurship. For instance, it is difficult to see the availability of specialized legal advice as a deal breaker for a new taxi firm, whereas such presence may be a prerequisite for the scale-up or internationalization of a game developer. A general finding in the literature is indeed that the diversity of economic activity in larger city regions appears to matter more for start-up activity in high-tech and knowledge-intensive industries (see, e.g., Andersson et al. 2019b).

To be sure, there are also negative effects of being in dense areas such as congestion and higher prices of land and real estate. When applying a population variable on the right-hand side of a regression, we consequently identify the net of all these effects.

\subsection{Social but Real: Local Informal Institutions}

The entrepreneurial potential of a region is not automatically realized simply because the fundamental factors are in place. A successful region still requires entrepreneurs who identify and act on opportunities: a process that requires knowledge and courage at the very least, both of which may be supplied via social networks. If a culture conducive to entrepreneurship takes root in a region, we may think of it as an informal local institution in the sense that it "governs" the economic fundamentals of the region. 
A burgeoning literature indicates that as places are characterized by different fundamentals, such as varying industrial structures, their social fabrics will start to diverge as well. Over time, regional support systems, legitimacy among the population, and other factors of the local milieu are adapted to be conducive to entrepreneurship in regions that are dense in entrepreneurs (Sorenson 2017). The social aspects of this process have interested researchers from different fields: entrepreneurial ecosystems, entrepreneurship cultures, and regional innovation systems.

An early observer of divergences in local industriousness was Alfred Marshall (1920) who identified what he called industrial districts, within which knowledge is refined over time in a social process (IV.X.7):

Good work is rightly appreciated, inventions and improvements in machinery, in processes and the general organization of the business have their merits promptly discussed: if one man starts a new idea, it is taken up by others and combined with suggestions of their own; and thus it becomes the source of further new ideas.

In Marshall's analysis, the initial conditions were conceived of as mainly geographic. Natural preconditions had motivated some initial investment. Then skills and complementary skills are attracted, and the local economy is eventually sustained by agglomeration economies.

When Chinitz (1961) analyzed differences in entrepreneurship between New York and Pittsburgh, he departed from observed differences in industrial geography. He suggested that different local industry structures would breed substantially different local entrepreneurs with varying frequencies. He suggested that entrepreneurs would be more effective in industries that were competitively organized, rather than oligopolistic, in nature. He juxtaposed the apparel industry that produced many entrepreneurs with the primary metals industry that produced few. This process was path-dependent and potentially persistent because of intergenerational transmission of entrepreneurial values and because of a culture of entrepreneurship, including positive attitudes to entrepreneurs in the local economy. For these reasons, Chinitz argued, diversified places like New York would have more entrepreneurs compared to manufacturing towns like Pittsburgh via feedback effects from the local industry structure, where dynamic effects emerged through transmission of skills and attitudes where many entrepreneurs where active. Following Chinitz's (1961) analysis and claim that Pittsburgh's dominance in steel was an important determinant of its subsequent lack of entrepreneurs, Glaeser et al. (2015) use distance to mining sites in 1900 as an exogenous instrument that is strongly correlated with modern-day average firm size.

Other studies in this field have analyzed the persistence of regional start-up rates as such and concluded that persistence of entrepreneurship is strong at the regional level. This literature has generally taken as suggestive evidence a "culture" that things change slowly over time and that "the case for culture" is particularly strong in places that have been subject to much turbulence such as a war-torn and communistrun Germany over the twentieth century (Fritsch and Wyrwich 2014). 
The learning mechanism described above has one crucial thing in common with network externalities: they occur regularly only among people who are located in close proximity to each other. This particularity of social networks implies that at least parts of any network peer effects in entrepreneurship should be observed at the neighborhood level, simply because neighbors are more likely to be in each other's networks and more likely to rub off on each other's behavior even in the absence of any formal connections between them. At the same time, it should be recognized that social network effects may also be confined to specific groups of people, even in a neighborhood. For example, there is plenty of evidence that immigrant entrepreneurs draw on resources through their social networks to other immigrants, often of the same ethnic group (Portes 1995). Co-location in small areas may thus not be sufficient for social network effects. In some cases, social network effects require a combination of low social distance and low physical distance. The rather large literature on ethnic enclaves and immigrant self-employment provides several examples research that builds on such ideas (see, e.g., Andersson et al. 2017; Toussaint-Comeau 2008).

\subsection{Local Formal Institutions: Permits and Politics}

As pointed out by North (North 1990), institutions (by which he meant any humanly devised constraint that shapes our conduct) interact with organizations (by which he meant political, economic, and social bodies). The interaction between local informal institutions and political organization remains an understudied area.

Like-minded people are prone to sorting themselves into the same places, and places further exert conformity on its people. This conformism of local informal institutions is likely to find its way into formal institutions over longer time periods. There are several avenues that the effects on formal institutions could take, including most obviously voting (in ballots and with feet), but also through informal channels such as complaints and praise, informal network activity, and so on.

By strengthening and amending local formal institutions a local government may in principle improve its position either by strengthening entrepreneurship within the local milieu or by attracting new entrepreneurs from other places. In order to understand these effects, first we need to investigate exactly which local institutions are determined at the local level. Most notably, local governments tend to have an important impact on regulations, whether in terms of how to devise them or how to enforce nationally imposed regulations. Such regulations include, for instance, building regulations and zoning laws (Andersson and Henrekson 2015).

\subsection{The "Correct" Spatial Level of Observation}

We should note at this point that the spatial scale of many effects outlined in this section is at this point still ambiguous. Historically, the analysis of labor market regions (and before that countries) where a necessity simply because "that's where 
the data were." As our data sources are getting increasingly flexible and even fully geocoded, researchers are no longer constrained by administrative units. When we are constrained by data aggregated at a high level, we risk being able to isolate only an outcome and infer the mechanisms conceptually. There are at least two ways that more disaggregated data sources may help us in this regard.

First, high-resolution data improve our analysis of spillovers and network effects where these need to be inferred. With neighborhood-level data, we can keep higherlevel effects constant, but not the other way around other than imperfectly and inelegantly. For instance, if we are interested in assessing the relative importance of sharing, matching, and learning, then by keeping region-level characteristics constant, we can analyze the learning component in isolation under the assumption that sharing and matching occur at a higher level of regional hierarchy. Ideally this practice takes us closer to the mechanism human capital spillovers. Other than keeping other key factors constant, there is an empirical reason to analyze neighborhoods as well. The neighborhood level, properly conceived, often generates enough within variation, meaning that we do not have to restrict our analyses to people who move between regions.

Second and relating to the last point, moving within a region is different from moving between regions. When performing research in the spatial sciences, a move is a wonderful thing, as it signifies an optimization decision. But by that logic, someone who moved within a region is at least content enough with the factors at the regional level not to skip town. Much of the migration literature has not simply focused on inter-regional moves but defined a move to be inter-regional in the first place. If we are interested in assessing entrepreneurs' preferences for accessing resources such as urban amenities, for instance, then presumably we may analyze whether their within-region moves correspond to our predictions. This practice will suppress some of the endogeneity issues built into inter-regional migration.

In the entrepreneurship literature, there has been a recent drive to follow parts of the literature on the attenuation of agglomeration externalities (e.g., Arzaghi and Henderson 2008; Andersson et al. 2019a) and to "open up" whole cities and regions in order to analyze entrepreneurship outcomes a fine spatial level. For example, in analysis of the geography of the quality of entrepreneurship in the USA, Guzman and Stern (2015) use novel data at a microgeographic level. They conclude that "our results highlight the micro-geography of the quality of entrepreneurship and suggest that clusters of entrepreneurial quality may benefit from being analyzed at a very low level of aggregation" and that "examining the factors that shape the boundaries of high-quality entrepreneurship is an important area for future research" (ibid. p,39).

\section{$4 \quad$ Concluding Remarks}

This chapter has discussed the role of entrepreneurship in economic geography. Regardless of anyone's interpretation of direction of the effect, productive and particularly high-impact entrepreneurship characterizes successful regions and is absent in failing ones. Little regional development seems to take place without an 
improved entrepreneurial base, and most if not all "places that don't matter" (Rodríguez-Pose 2018) seem to have been accompanied by weak local entrepreneurship. It seems then that local and national policymakers have much in common with researchers in economic geography: in order to "get it," they need to make sense of entrepreneurship.

We draw four broad conclusions from our analysis:

First, human capital is key. New firms are started by people. The geography of entrepreneurship is fundamentally influenced by how entrepreneurship-prone people sort across regions, by the opportunities that different regions provide when it comes to individuals' accumulation of knowledge and experience relevant for entrepreneurship, as well as by the social and policy environment that may incentivize and support individual action. A successful region needs to ideally produce, and definitely access, skilled and entrepreneurial individuals that act on perceived opportunities. However, many questions remain about the how.

Second, both the frequency and the quality of entrepreneurship matter. Most empirical researchers have focused their efforts on determinants and effects of increased frequency of new firm formation. Small businesses without growth ambitions are often entrepreneurial and important for regional development. But our knowledge of how regional factors influence the emergence and growth ambitions of so-called high-impact entrepreneurs remains an understudied area.

Third, spatial scales can inform the analysis. If we want to get down to mechanisms in our analyses, then finely geocoded data sources may greatly help our efforts. Not only can flexible data help isolating effects that are only present in the microgeography; they can also generate spatial units that produce meaningful statistical variation given a shock (say, the entry of a handful of entrepreneurs) that would be considered noise in a regional measure.

Fourth, entrepreneurship is a field characterized by endogeneity. Many causes and effects of entrepreneurship are subject to intense debate regarding direction of the effect. Connections between new firm formation and growth belonged here until quite recently, as do currently areas such as the connections between entrepreneurship and a local "culture," as well as between entrepreneurship and enacted regional policies. Researchers that manage to tease out the direction of causality where our knowledge is missing will be in pool position in the future.

\section{$5 \quad$ Cross-References}

Clusters, Local Districts, and Innovative Milieux

- Factor Mobility and Migration Models

- Knowledge Flows, Knowledge Externalities, and Regional Economic Development

- Knowledge Spillovers Informed by Network Theory and Social Network Analysis

Local Social Capital and Regional Development

$>$ The Geography of Innovation 


\section{References}

Acs ZJ, Braunerhjelm P, Audretsch DB, Carlsson B (2009) The knowledge spillover theory of entrepreneurship. Small Bus Econ 32(1):15-30

Aldrich H, Cater J, Jones T, Mc Evoy D, Velleman P (1985) Ethnic residential concentration and the protected market hypothesis. Soc Forces 63(4):996-1009

Andersson M, Henrekson M (2015) Local competitiveness fostered through local institutions for entrepreneurship. In: Audretsch DB, Link AN, Walshok M (eds) Oxford handbook of local competitiveness. Oxford University Press, Oxford, pp 145-190

Andersson M, Koster S (2016) Are start-ups the same everywhere? The urban-rural skill gap in Swedish entrepreneurship. In: Geographies of entrepreneurship. Routledge, London, pp $140-160$

Andersson M, Larsson JP (2016) Local entrepreneurship clusters in cities. J Econ Geogr 16 (1):39-66

Andersson M, Larsson JP, Öner Ö (2017) Ethnic enclaves and immigrant self-employment: a neighborhood analysis of enclave size and quality (No. 1195). IFN Working Paper

Andersson M, Larsson JP, Wernberg J (2019a) The economic microgeography of diversity and specialization externalities-firm-level evidence from Swedish cities. Res Policy 48 (6): $1385-1398$

Andersson M, Lavesson N, Partridge MD (2019b) Local Rates of New Firm Formation: An Empirical Exploration using Swedish Data (No. 1290). Research Institute of Industrial Economics

Arzaghi M, Henderson JV (2008) Networking off Madison avenue. Rev Econ Stud 75 (4):1011-1038

Chinitz B (1961) Contrasts in agglomeration: New York and Pittsburgh. Am Econ Rev 51 (2):279-289

Duranton G, Puga D (2004) Micro-foundations of urban agglomeration economies. In V. Henderson \& J.-F. Thisse (Eds.), Handbook of Regional and Urban Economics (Vol. 4, pp. 2063-2017). Amsterdam: North Holland

Fritsch M (2013) New business formation and regional development: a survey and assessment of the evidence. Found Trends Entrep 9(3):249-364

Fritsch M, Storey DJ (2014) Entrepreneurship in a regional context: historical roots, recent developments and future challenges. Reg Stud 48(6):939-954

Fritsch M, Wyrwich M (2014) The long persistence of regional levels of entrepreneurship: Germany, 1925-2005. Reg Stud 48(6):955-973

Gennaioli N, La Porta R, Lopez-de-Silanes F, Shleifer A (2013) Human capital and regional development. Q J Econ 128(1):105-164

Glaeser EL, Kerr SP, Kerr WR (2015) Entrepreneurship and urban growth: an empirical assessment with historical mines. Rev Econ Stat 97(2):498-520

Guzman J, Stern S (2015) Nowcasting and placecasting entrepreneurial quality and performance (no. w20954). National Bureau of Economic Research

Henrekson M, Sanandaji T (2014) Small business activity does not measure entrepreneurship. Proc Natl Acad Sci 111(5):1760-1765

Jacobs J (1969) The economy of cities. Random House/Vintage Books, New York

Kerr WR, Nanda R, Rhodes-Kropf M (2014) Entrepreneurship as experimentation. J Econ Perspect 28(3):25-48

Kirzner I (1973) Competition and entrepreneurship. The University of Chicago Press, London

Lee YS (2017) Entrepreneurship, small businesses and economic growth in cities. J Econ Geogr 17 (2):311-343

Lindholm-Dahlstrand Å, Andersson M, Carlsson B (2019) Entrepreneurial experimentation: a key function in systems of innovation. Small Bus Econ 53(3):591-610

Marshall A (1920) Principles of economics, 8th edn. Macmillan, London

Minniti M (2005) Entrepreneurship and network externalities. J Econ Behav Organ 57(1):1-27 
North DC (1990) Institutions, institutional change and economic performance. Political economy of institutions and decisions. Cambridge University Press, New York

Obschonka M, Schmitt-Rodermund E, Silbereisen RK, Gosling SD, Potter J (2013) The regional distribution and correlates of an entrepreneurship-prone personality profile in the United States, Germany, and the United Kingdom: a socioecological perspective. J Pers Soc Psychol 105 (1):104-122

Portes A (ed) (1995) The economic sociology of immigration: Essays on networks, ethnicity, and entrepreneurship. Russell Sage Foundation, New York

Rodríguez-Pose A (2018) The revenge of the places that don't matter (and what to do about it). Camb J Reg Econ Soc 11(1):189-209

Sorenson O (2017) Regional ecologies of entrepreneurship. J Econ Geogr 17(5):959-974

Toussaint-Comeau M (2008) Do ethnic enclaves and networks promote immigrant selfemployment? Econ Perspect 32(4):30-50

Wennekers S, Thurik R (1999) Linking entrepreneurship and economic growth. Small Bus Econ 13 (1):27-56 